\title{
Research on the Attitudes of the Elderly towards Interprofessional Cooperation and Collaborative Pharmacy Practices: Cross-sectional Study in Serbia
}

\author{
Velibor O Ilić*, Ljiljana Tasić, Valentina Marinković \\ Department of Social Pharmacy and Pharmaceutical Legislation, Faculty of Pharmacy, University of Belgrade, Vojvode Stepe, \\ Belgrade, SERBIA.
}

\begin{abstract}
Background: Population aging is taking place at the highest historical rates, while growing needs for healthcare by the elderly put added and immense pressure predominantly on the primary care. Higher level of interprofessional collaboration is expected to improve healthcare system performance and to provide adequate delivery of healthcare for the elderly. This was the main driver for implementing the interprofessional collaborative models by many countries. However, these models need to be patient-centered and more focused on "what matters" to patient. This study aims to identify the attitudes of the elderly people $(65+)$ towards interprofessional collaboration (IPC), namely collaborative pharmacy practice (CPP). Methods: A cross-sectional study was carried out in Serbia from May 2017 to July 2017, taking place in five Geriatric Centers. A total of 187 men and women (average age 76.2 years), were interviewed using a structured questionnaire. Results: Respondents noted the insufficient visibility of the elderly and insufficient informing as the biggest problems faced by the elderly within the system of health and social care. The significant difference by gender and education was found in several questions. However, respondents believed that the efficiency of the healthcare system would significantly increase if there were closer cooperation and coordination between doctors, pharmacists and other healthcare workers. Conclusion: The lack of collaborative pharmacy practice represents a significant unused potential for improving healthcare for the elderly considerably, which under the conditions of limited resources may stipulate organizational changes or corrections.
\end{abstract}

Key words: Cross-sectional survey, Collaborative practice, Healthcare, Attitudes, Elderly.

\section{INTRODUCTION}

Population aging is taking place at the highest historical rates, ${ }^{1}$ due to the increasing life expectancy and declining birth rates. ${ }^{2}$ The percentage of the population over 60 is growing faster than any other age group in almost all countries. ${ }^{3}$ By 2050, it is expected that every fifth person will be older than 60. ${ }^{4}$ Population aging is associated with increased morbidity or comorbidity and higher incidence and prevalence of chronic diseases. ${ }^{5}$ In order for healthcare systems to respond effectively to the growing needs for healthcare by the elderly population, higher level of interprofessional collaboration is expected. ${ }^{6}$ An average of $81 \%$ Europeans (for Serbia's bordering countries Croatia $71 \%$, Hungary 80\%, Romania $74 \%$ and Bulgaria 78\%) prefers to be cared for in their own homes either by relatives or professionals and only $8 \%$ (Croatia $15 \%$, Hungary $10 \%$, Romania $6 \%$ and Bulgaria 5\%) prefers to be cared for in a long-term care institution. ${ }^{7}$ Higher level of collaborative practice could enable patients/clients to longer stay in their own homes. ${ }^{8}$ In Serbia this issue is even more important, as more people are staying at home due to insufficient capacity of longterm care institutions $(0,76 \%$ of the elderly were able to secure accommodations in
Submission Date: 08-02-2020; Revision Date: 08-10-2020; Accepted Date: 06-01-2021

DOI: 10.5530/ijper.55.1.31 Correspondence: Mr. Velibor O llić Department of Social Pharmacy and

Pharmaceutical Legislation, Faculty of Pharmacy, University of Belgrade, Vojvode Stepe-450, 11221 Belgrade, SERBIA.

Phone no: +3816431494 35

Email id: ivelibor@gmail.com

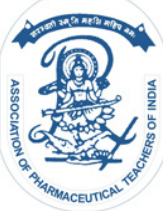

www.ijper.org 
geriatric centers). ${ }^{9}$ Also, available capacities are unevenly distributed, being predominately located at the north of Serbia. ${ }^{10}$ While, many countries have implemented IPC models, Serbia does not have a comprehensive longterm care policy that addresses the needs of the elderly population. ${ }^{9}$

Collaborative practice has been known by many names including interprofessional practice and inter professional collaboration. ${ }^{11}$ The Canadian Interprofessional Health Collaborative defines interprofessional collaboration in the healthcare and social services system as a "partnership between one team of providers of healthcare services and one patient/client in a mutually participative collaborative and coordinated approach in order to make joint decisions on health and social issues". ${ }^{12}$ This definition can be misleading, as it should include social care providers and it should highlight clients and families as active and key participants of the interprofessional collaboration process. ${ }^{13}$ In that regard, little evidence is found that researchers have conceptualized clients and family as members of IPC. ${ }^{13,14}$ However, sharing the decision-making process with patients, demands a shift in thinking for both care providers and patients. ${ }^{15}$ Since there is no universal IPC or CPP model to meet the needs of every population of patients, the models differ significantly in focus and implementation among context-specific patient groups. ${ }^{16,17}$

When talking about existing IPC in elderly care, Ploeg J. et $a .^{13}$ are providing interesting insights into worldwide practice, where most of the discussed models are patient centered, but with larger variation of involved members. In 2000, Japanese government implemented mandatory long-term care insurance (LTCI) which encourages the elderly to use services by their own choice. ${ }^{18}$ Similar objective had a Danish government which resulted in introducing a "free-choice model" in order to provide the elderly with a free choice of care providers. ${ }^{19,20}$ Swedish healthcare system has professional team collaboration, which includes the older person when it comes to the care planning upon discharge from the hospital. ${ }^{21}$ Virtual wards in the $\mathrm{UK}^{22}$ and IPC in New Zealand ${ }^{23}$ are both aiming to provide seamless (transitional) care to elderly clients. The American program of All-Inclusive Care for the Elderly (PACE) provides "continuous care and services offering individuals eligible for nursing home care the option of continuing to live in the community". ${ }^{24}$ IMPACT model (Interprofessional Model of Practice for Aging and Complex Treatments), initiated in 2008 at Sunnybrook Health Science Centre in Toronto, is the most complete of the all above mentioned models, because it also involves pharmacist and social worker as its participants. ${ }^{25}$

While, more IPC research reporting patient-oriented outcomes $^{17}$ and outcome indicators ${ }^{8}$ are needed, "integrated models of care have the potential to improve the processes of care and reduce hospital or long-term care use". ${ }^{17}$ In that matter, inclusion of pharmacists and general practitioners as members of IPC, showed significant effects on outcome indicators. ${ }^{26,27}$ Evidence $^{28-37}$ shows that the collaborative pharmacy practice models could have positive effects in reducing medical errors, including medication errors of inappropriate prescribing for the elderly patients. These models could provide the clinical and economic benefits, such as reducing morbidity/mortality and costs. ${ }^{28-37}$ However, a comprehensive overview of the available literature ${ }^{38}$ demonstrated that models of collaborative pharmacy practice in healthcare and social services for the elderly in developing countries such as the Republic of Serbia and in most of the developed countries in continental Europe, were still not considered as a solution to the systemic problems.

For the elderly patients, as members of the integrated IPC model, it is necessary to have clear understanding of who the IPC team members are, what is their role and which services they can provide. ${ }^{13}$ Further on, WHO has recognized attitudes of the older adults as a key component in optimizing healthy ageing, ${ }^{39}$ while services, system and policies are considered as an important component of the healthy ageing process. ${ }^{40,41}$ Therefore, qualitative studies are required to understand the experiences of the elderly with IPC models. ${ }^{13}$ Also, considering complexity of the healthcare and social care system, there is evident need to help elderly people to understand their role in prioritizing their needs. ${ }^{13}$

There is lack of studies investigating attitudes of the users of healthcare and social services in Serbia. The Annual reports on improving the performance quality of healthcare institutions, conducted and published by the Institute for Public Health of Serbia "Dr. Milan Jovanović-Batut", ${ }^{42,43}$ published data on the level of cooperation satisfaction between healthcare workers. In the last few years, there is a positive trend among researchers who see interprofessional education in Serbia as initial step towards the improvement of collaborative practice. ${ }^{44-46}$ The analysis on users `satisfaction regarding healthcare service provided by publicly owned healthcare institutions, was predominately focusing on patient satisfaction to individual healthcare service provided. ${ }^{47}$ However, there are no surveys addressing the attitudes of the elderly users of the healthcare and social services 
regarding their "status" related to the health and social policy of the Republic of Serbia, as well as regarding their perceptions of the team work of healthcare workers within the context of improving seniors` quality of life. In order to give our contribution to resolution of the aforementioned issues, authors found necessary to explore the attitudes of elderly about interprofessional collaboration and collaborative practices and therefore identify the opportunities, methods and solutions for improvement.

However, current literature has not provided us with an adequate instrument for use in this broad capacity. After evaluating numerous developed instruments for measuring varying aspects of IPC, Thannhauser J. et al. ${ }^{48}$ have found that most of the tools (questionnaires predominately) were lacking sufficient information regarding their psychometric properties. Most of the questionnaires for health care related research ${ }^{49-51}$ were designed to assess only collaboration within a narrow health discipline and almost exclusively just from the perspective of healthcare professionals, leaving patients' attitudes toward healthcare collaboration unexplored. As many of the developed questionnaires were used only once and as some papers have not included questionnaires in the appendix, the usability of those questionnaires in our research is limited. Therefore, the authors found necessary for the purpose of this study to develop a questionnaire that can be a valuable tool and resource for further research on CPP and IPC.

This study aims to identify the attitudes about interprofessional collaboration and collaborative pharmacy practices among the elderly care home users and the role of socio-demographic factors on those attitudes, using previously developed questionnaire.

\section{MATERIALS AND METHODS}

A cross-sectional study was carried out using a representative sample of senior citizens (aged 65+ years) living in public Care Homes.The research was carried out in the Republic of Serbia, in its northern region of Vojvodina, which consists of four sub-regions: Banat, Backa, Srem and Macva. Using a stratified sampling method, the previously developed questionnaire was distributed to five publicly owned geriatric centers (GC Zrenjanin, GC Kikinda, GC Novi Sad, GC Subotica and GC Ruma) located in cities within the four previously mentioned geographic regions (Banat, Backa, Srem and Macva), thus encompassing the largest geriatric centers and their individual geriatric homes (elderly care homes) in the territory of AP Vojvodina. The inclusion criteria for the respondents was as follows: being older than 65 years of age and were evaluated by the healthcare and social services workers of the geriatric centers to be cognitively preserved to understand the questions from the Questionnaire, Volunteers` willingness to participate, ability to use the Serbian language and ability to speak clearly. At each GC there was one person delegated (a healthcare or social worker) who was familiar with the research protocol and who would read the questions to respondents and fill out the questionnaire based on respondents`answers.

\section{Data collection}

A total of 200 Questionnaires (40 Questionnaires per GC) were mailed out by postal service or delivered in person. From May 2017 to July 2017 a total of 187 Questionnaires were collected. The response rate was $93.5 \%$. Answers of two respondents whose answers were extremely far from the $95 \%$ interval were eliminated from the statistical analysis $(n=185)$.

\section{Questionnaire development}

The questionnaire, as the survey instrument for the purpose of this research, was developed and tested by the authors. The Delphi method was used for the development and preliminary validation of the questionnaire, within the four rounds of meetings of the expert team, which took place from October 2016 to February 2017. The development of the questionnaire was carried out in four steps: (i) Expert team formation, (ii) Identification of key problems and barriers to interprofessional and interdisciplinary cooperation between the healthcare and social services, (iii) Questions assessment, (iv) Preliminary validation of the questionnaire. As the first step, an interprofessional and interdisciplinary team of experts convened and performed the identification (in a holistic manner) of the biggest challenges and obstacles experienced in practice (providing further potential questions for the questionnaire), regarding interprofessional and interdisciplinary cooperation within the scope of health- and social care for the elderly. In that regard, a team of 8 participants was created, comprising: A moderator, who managed the entire analyzing process (the principal investigator); experts on the process of dispensing medicines (pharmacists with Bachelor's or Master`s degree employed in private and state-owned community pharmacies in the Republic of Serbia); experts on diagnosis, prescribing therapy and treatment (general practitioners and/or physicians specialists), health professionals (nurses/medical technicians) involved in care providing, preparation and application of prescribed therapies on patients in geriatric homes; 
as well as social services experts (social workers); and an elderly person. Potential questions that would be included in the questionnaire, which were generated during the arranged meetings, were organized into three categories: (i) socio-demographic features of respondents, (ii) elderly people and healthcare and social policy (iii) attitudes and beliefs of the elderly as patients/geriatric users regarding the teamwork and interprofessional practice of healthcare workers within the context of improving the quality of life of the elderly. As the third step, the assessment process started at a joint group meeting, by grading the questions on a scale from 5 to 10 . The questions with an average grade greater than the threshold values of 7-8, became part of the final questionnaire automatically. Since there were no questions graded below the threshold values, the team gave its approval to the final form and to the contents of the questionnaire. After that, a preliminary validation of the questionnaire was performed on a sample of 40 respondents who were users of the geriatric center, by using the Cronbach`s Alpha as a statistical parameter for the reliability analysis.

In order to establish the reliability of our questionnaire, the Cronbach alpha coefficient and ICC (Intraclass correlation) coefficient were calculated. Preliminary validation of the questionnaire $(n=40)$ determined the high Cronbach`s Alpha value of 0.774. Cronbach`s Alpha value on our entire respondent sample $(n=185)$ was relatively high value of 0.736 . Also we used the analysis of change in the Cronbach `s Alpha coeficient by eliminating single question to further test questionnaire consistency and reliability (change was within the range 0.721 to 0.802 ) Also, we used intraclass correlation coefficient to test the compactness and high reliability of the questionnaire (ICC $=0.749 ; p<0.01$ ). EFA (exploratory factor analysis) was performed in order to find the importance and pole of each question building our Questionnaire. It highlighted two significant factors explaining $53 \%$ of the variability of the entire model. Also, the correlation between questions was calculated. The significant level was considered to be always 0.05 .

\section{Data analysis}

Data were analyzed using the SPSS 22.0 software package. We used descriptive statistical methods and methods of inferential statistics (parametric or non-parametric, depending on the normality of data distribution which we controlled using Kolmogorov Smirnov test). We used the parametric t-test for numerical data and the chi square test for nominal data. The level of significance was set to $p$-value $<0.05$.

\section{Ethical Considerations}

The Ethics Committee for Biomedical Research from the Faculty of Pharmacy, at the University of Belgrade approved the research protocol and the created Questionnaire, which was used as a survey instrument (approval number 1313/1 from 6.7.2017.). In addition, after learning the details of the research protocol, a written approval to conduct the survey in the facilities of the Geriatric Centers was obtained from all directors of the aforementioned Geriatric Centers. Therefore, after obtaining the necessary approvals, the Questionnaires were distributed by mail or in person. The Research protocol with detailed explanation of the voluntary participation in the survey was part of the questionnaire as a cover page. It was presented in native language to the respondents both verbally and in paper. Filling out the questionnaire was completely voluntary and the collected data was used aggregately and solely for scientific and research purposes, all being stated in the research protocol. Respondents were informed that by completing the questionnaire, they are giving their informed consent to participate in the research.

\section{RESULTS}

The distribution of age, gender and educational attainment in our sample was balanced (Table 1). The sample size was adequate, while the women were slightly older than men and were more represented in the sample $(n=110)$, Table 1.

There were no statistically significant differences related to gender, as compared to the average age $(t=1.070$; $p>0.05)$, even though the female respondents were somewhat older. Additionally, there were no significant differences by gender in regard to education $\left(\chi^{2}=\right.$ $0.620 ; p>0.05)$, since the respondents of both genders

\begin{tabular}{|c|c|c|c|c|}
\hline Education level & Values & Male & Female & Total \\
\hline \multirow{2}{*}{ High school ${ }^{a}$} & $\mathrm{n}$ & 78 & 49 & 127 \\
\hline & $\%$ & $70.9 \%$ & $65.3 \%$ & $67.9 \%$ \\
\hline \multirow{2}{*}{ Associate $^{b}$} & $\mathrm{n}$ & 14 & 10 & 24 \\
\hline & $\%$ & $12.7 \%$ & $13.3 \%$ & $13.4 \%$ \\
\hline \multirow{2}{*}{ University $^{c}$} & $\mathrm{n}$ & 18 & 16 & 34 \\
\hline & $\%$ & $16.3 \%$ & $21.3 \%$ & $18.7 \%$ \\
\hline \multirow{2}{*}{ Total } & $\mathrm{n}$ & 110 & 75 & 185 \\
\hline & $\%$ & $59.5 \%$ & $40.5 \%$ & $100.0 \%$ \\
\hline \multirow{2}{*}{ Age } & Mean & 76.4 & 75.6 & 76.2 \\
\hline & $S D$ & 6.2 & 6.9 & 6.4 \\
\hline
\end{tabular}

In Table 1, absolute and relative frequencies are presented. aHigh school (8-12 years of education). ${ }^{b}$ Associate (12-15 years of education). 'University (At least 16 years of education). 
predominantly indicated high school and associate degrees in their responses (over $80 \%$ of both genders). All questions presented in the Table 2 were scored in the same way, using the Likert scale. The minimum value (score 1) would mean that the respondents believe that there is a complete absence of CPP and IPC and/or have negative attitudes towards CPP and IPC. The maximum value (score 5) would express an ideal situation of fully implemented CPP and IPC, or positive attitudes of respondents toward CPP and IPC implementation.

Ranking the significance of the services that the Office for the Elderly would provide (the most significant service was marked with 1)

The information distribution was ranked as the most important service that the Office for the Elderly (OfE) would provide, since 52 respondents graded this service with 1 . The initiative to increase the accommodation capacities of Geriatric Center was chosen by 47 respondents as the least important service that the OfE would provide (Figure 1).

Ranking the significance of the problems the elderly are faced with, within the framework of Health and Social Policy (the most significant problem was marked with 1)
The insufficient visibility of the elderly was specifically identified by 48 respondents (rank 1) as the greatest problem the elderly are facing within the scope of the healthcare and social policies. Almost a third of all participants $(n=56)$ ranked insufficient volunteerism (rank $6)$, as the least significant problem (Figure 2).

There were significant gender differences in responses regarding the biggest barriers on creating the health and social care policy towards elderly $(\chi 2=13.542 ; p<0.01)$. Female respondents indicated that indifference of the society at large and insufficient political will (50.0\%) were the biggest barriers against implementing the Healthcare and Social Policies primarily, while the lowest barrier was the lack of staffing $(9.3 \%)$. Male respondents expressed that the most significant barrier was the lack of financial resources and insufficient coordination (55.0\%). On the other hand, untimely informing was the least reason to complain about $(6.7 \%)$.

There were significant gender disparities in relation to the respondents ' choice of the most needed institution regarding elderly $\left(\chi^{2}=8.186 ; p<0.05\right)$. Female respondents were placing geriatrics institute and then geriatric hospital in the first place $(65.0 \%)$. According

\begin{tabular}{|c|c|c|c|c|c|}
\hline Questions & Minimum & Maximum & Mean & MED & SD \\
\hline $\begin{array}{c}\text { q5b. Level of your satisfaction with the services provided } \\
\text { within the Health- and Social Care? }\end{array}$ & 1.00 & 5.00 & 3.02 & 3.00 & 1.34 \\
\hline $\begin{array}{l}\text { q9b. Would you join a volunteering activity geared towards } \\
\text { improving the quality of life of the elderly? }\end{array}$ & 1.00 & 5.00 & 3.53 & 4.00 & 0.91 \\
\hline $\begin{array}{l}\text { q12. Would a pharmacist, as a part of the health care } \\
\text { workers team improve health-related outcomes and quality } \\
\text { of life of the elderly? }\end{array}$ & 1.00 & 5.00 & 3.58 & 3.40 & 0.90 \\
\hline $\begin{array}{l}\text { q13. Rate the information provided by doctors and } \\
\text { pharmacists regarding products prescribed/recommended } \\
\text { to elderly patients }\end{array}$ & 1.00 & 5.00 & 3.32 & 3.10 & 0.84 \\
\hline $\begin{array}{l}\text { q14. Would the efficiency of the Health Care improve, if } \\
\text { pharmacists provided counseling services regarding the } \\
\text { rational and safe use of pharmaceutical products for the } \\
\text { elderly patients }\end{array}$ & 1.00 & 5.00 & 3.75 & 3.80 & 0.91 \\
\hline $\begin{array}{l}\text { q15. Assess the efficiency of the Health Care System } \\
\text { in regards to the time spent on prescribing and issuing } \\
\text { pharmaceutical products to the elderly }\end{array}$ & 1.00 & 5.00 & 2.80 & 3.00 & 0.83 \\
\hline $\begin{array}{l}\text { q16. Have you experienced scenario where pharmacist } \\
\text { notices a certain oversight in doctor's prescription/ } \\
\text { recommendation } \\
\text { and asks you to return to your doctor in order to have him/ } \\
\text { her correct the error or to have a therapy revised? }\end{array}$ & 1.00 & 5.00 & 2.21 & 2.50 & 1.07 \\
\hline $\begin{array}{l}\text { q17. Would the efficiency of the Healthcare system } \\
\text { increase if there were an even better cooperation and } \\
\text { coordination between doctors and pharmacists and other } \\
\text { health care workers providing care for the elderly? }\end{array}$ & 1.00 & 5.00 & 3.76 & 3.65 & 0.83 \\
\hline $\begin{array}{c}\text { q18. Have you experienced a power outage or a computer } \\
\text { system crash at the Community Health Care Center or a } \\
\text { pharmacy? }\end{array}$ & 1.00 & 5.00 & 2.02 & 2.20 & 0.95 \\
\hline
\end{tabular}


to male respondents, the most significant role in improving the quality of life belonged to geriatrics institute and specialized counseling centers (community bealth centers and community pharmacy) $(65.0 \%)$.

There were significant differences based on gender, regarding the participation in volunteering activity. $\left(\chi^{2}=8.038 ; p<0.01\right)$ and that came because of men participating far more frequently in some volunteering activities than women in our line of work.

When comparing the average scores of the questions with an eventual rating option using the Likert scale (Table 2 and Table 3), a statistically significant difference by gender was shown in only two questions: $5 b$ and 15 . Compared to female respondents, male respondents were more satisfied with healthcare and social care services that they have used (question 5b). Female respondents were more satisfied than male respondents, with the time they waited for prescribing and dispensing the pharmaceuticals (question 15).

Respondents believed that a pharmacist, as a member of the healthcare team, could improve the health outcomes and quality of life of the elderly (graded with 3.58), (Table 3). They also evaluated the physicians` and pharmacists`advice about drugs, medical devices and dietary supplements as good (score 3.30). Respondents considered that the efficiency of healthcare would increase greatly if pharmacists could provide additional counseling services at the pharmacy on the rational and safe application of pharmaceutical products for the elderly (score 3.78). They considered the efficiency of the healthcare system as good (score 2.78) regarding the time spent on prescribing and issuing medications. However, the respondents pointed out that they were rarely (score 2.22) in a situation where a pharmacist noticed a certain oversight in the prescription or recommendation of drugs, medical devices, or dietary supplements and asked them to return to the doctor in order to have the doctor correct the error, or reassess the therapy. Respondents believed that the efficiency of the healthcare system would increase significantly (score 3.76) if there was a closer cooperation and coordination between doctors, pharmacists and other healthcare workers. Additionally, respondents pointed out that they were seldom in a situation (score 2.01) where the community health centers or pharmacies had difficulties with the computer systems.

When respondents were asked which services of the OfE they would suggest (question 2), there were statistically significant differences in answers depending

\begin{tabular}{|c|c|c|c|c|c|c|}
\hline Question & Gender & Mean & MED & SD & $\mathbf{t}$ & p \\
\hline \multirow{2}{*}{$q 5 b$} & $\mathrm{~F}$ & 3.38 & 3.20 & 0.94 & \multirow{2}{*}{2.488} & \multirow{2}{*}{$0.012^{*}$} \\
\hline & $M$ & 3.73 & 3.65 & 0.81 & & \\
\hline \multirow{2}{*}{$q 9 b$} & $\mathrm{~F}$ & 2.90 & 2.79 & 1.32 & \multirow{2}{*}{1.501} & \multirow{2}{*}{0.128} \\
\hline & $\mathrm{M}$ & 3.20 & 2.99 & 1.30 & & \\
\hline \multirow{2}{*}{ q12 } & $\mathrm{F}$ & 3.57 & 3.42 & 0.88 & \multirow{2}{*}{0.150} & \multirow{2}{*}{0.857} \\
\hline & $M$ & 3.60 & 3.52 & 0.91 & & \\
\hline \multirow{2}{*}{ q13 } & $\mathrm{F}$ & 3.32 & 3.40 & 0.76 & \multirow{2}{*}{0.365} & \multirow{2}{*}{0.717} \\
\hline & $M$ & 3.29 & 3.20 & 0.94 & & \\
\hline \multirow{2}{*}{$q 14$} & $F$ & 3.69 & 3.60 & 0.95 & \multirow{2}{*}{1.552} & \multirow{2}{*}{0.122} \\
\hline & $M$ & 3.88 & 3.70 & 0.86 & & \\
\hline \multirow{2}{*}{ q15 } & $\mathrm{F}$ & 2.92 & 2.87 & 0.85 & \multirow{2}{*}{2.013} & \multirow{2}{*}{$0.045^{\star}$} \\
\hline & $M$ & 2.65 & 2.50 & 0.76 & & \\
\hline \multirow{2}{*}{$q 16$} & $\mathrm{~F}$ & 2.15 & 2.10 & 1.00 & \multirow{2}{*}{0.829} & \multirow{2}{*}{0.408} \\
\hline & $M$ & 2.29 & 2.18 & 1.17 & & \\
\hline \multirow{2}{*}{$\mathrm{q} 17$} & $\mathrm{~F}$ & 3.73 & 3.77 & 0.80 & \multirow{2}{*}{0.402} & \multirow{2}{*}{0.639} \\
\hline & $M$ & 3.80 & 3.75 & 0.88 & & \\
\hline \multirow{2}{*}{ q18 } & $\mathrm{F}$ & 2.00 & 1.98 & 0.92 & \multirow{2}{*}{0.060} & \multirow[t]{2}{*}{0.955} \\
\hline & $M$ & 2.02 & 2.05 & 0.99 & & \\
\hline
\end{tabular}

In Table 3, mean values are presented. Five-point Likert scale was used where grade 1 was the lowest score, and grade 5 was the highest score 
on respondents` education $(\chi 2=22.103 ; p<0.05)$. The respondents with a high school degree and associate degrees predominately chose answers information distributor and initiator of an increase in geriatric center accommodations capacity (over 50.0\% of respondents). The respondents with university education proposed the following services of the OfE: driver of the strategy development for the protection of the elderly and information distributor (almost $60.0 \%$ of the answers).

The analysis (data not shown) showed that there were statistically significant differences by education when ranking the importance of $\mathrm{OfE}$ as a driver of the strategy development towards the elderly $\left(\chi^{2}=23.896 ; p<0.01\right)$. The subgroup with the highest level of education had the most respondents who ranked this role of the OfE as the most important $34.0 \%$ of respondents with a university degrees and only $12 \%$ with high school degrees followed by $9.4 \%$ with associate degrees).

The statistically significant differences by education were also present when ranking the importance of OfE as the initiator of an increase in geriatric center accommodations capacity $(\chi 2=18.293 ; p<0.01)$. Responder's subgroup with the highest level of education had the lowest number of respondents who ranked this role of the OfE as the most important $(8.6 \%$ of respondents with completed university degrees and $32.0 \%$ associate degrees or $19 \%$ with high school degrees).

Regarding willingness for volunteering services, the analysis (data not shown) also showed that there were statistically significant differences in answers by level of education $\left(\chi^{2}=5.465 ; p<0.05\right)$. The reason behind is that respondents with the high school degrees were less likely to participate in volunteering activities than those having associate degrees and university degrees.

Regarding the most needed institution of the healthcare and social care system according to respondents, the analysis (data not shown) showed that there were statistically significant differences in answers to that question depending on the level of education $\left(\chi^{2}=\right.$ 14.781; $p<0.05)$. Those differences are present because respondents with the high school and associate degrees named the institute for geriatrics as the most significant institution, while the specialized counseling centers were the second most significant institutions. Contrary, the respondents with the university degrees placed hospice in the first place.

\section{DISCUSSION}

Our results show that the elderly people feel that they are insufficiently "visible" and informed in social care system, while they are mostly satisfied with the provided healthcare services, although according to them, healthcare system would benefit from closer interprofessional cooperation between pharmacist and other healthcare professionals. These results need to be taken in consideration when planning collaborative practice models by decision makers. Insufficient "visibility" of elderly people in healthcare and social care system could indicate that system is insufficiently patient/ client centered or that there is inadequate delivery of healthcare and social care to every population group. This mater needs to be addressed in order to meet the needs of the elderly and world-wide recommendations for patient/client centered healthcare and social care system, ${ }^{6}$ health equity, ${ }^{52}$ and shared decision-making with patients. ${ }^{13,15}$

In particular, regarding our findings in section of the questionnaire describing the health and social policies in regard to elderly, a statistically significant difference in answers was observed in question 2 depending on respondents' education. The highly educated respondents suggested to the OfE to implement the service- driver of the strategy development for the protection of the elderly while the respondents with high school degrees and associate degrees considered the service of the initiator of an increase in geriatric center accommodation capacity as more important. These results need to be observed from the current situation in Serbia, where a comprehensive long-term care policy that would address the needs of the elderly population does not exist. ${ }^{9}$ According to the answers from highly educated responders, they have recognized this issue and they want a comprehensive policy as a solution for the improvement of health and social care for the elderly. However, the other respondents addressed insufficient accommodation capacities of geriatric centers $(0,76 \%$ of the elderly were able to secure accommodations in geriatric homes) $)^{9}$ as the main issue, which could be present due to the absence of national comprehensive long-term care policy. These results are in line with the findings of the National bureau of economic research, ${ }^{53}$ which confirm that education improves critical thinking skills and that more educated individuals appear to be better informed and make use of new health related information first. However, the same study found that the importance of education as determinant starts to fall sometime between ages 50 and 60 . Assertions from previous question, were also confirmed by the statistically significant results that were obtained and that are presented here, regarding the ranking of respondents' responses related to question 3 (services of OfE). Figure 1 displays graphically all the respondents' answers to that question. It also displays that the respondents considered Information distributor 
to be their first and second choice for the most important service of the OfE, provided that the Office established one. The importance of the information distributor or system mediator is recognized by Ploeg J. et al. According to them, "system navigator" should be included in any integrated care model to help patients/ clients and their families to manoeuvre through complex system networks. ${ }^{13}$ The answers to question 3 (Figure 1) match with the answers to question 7 (Figure 2), as the respondents identified the inefficient informing as the second most difficult problem faced by the elderly within the Health and Social Policies, while insufficient visibility of the elderly was their biggest issue and at the same time the most significant answer. Many aspects of neglect (followed by theme: being invisible) of elderly patients in long-term care were highlighted. ${ }^{54}$ Interestingly, although our findings are on a par with those claims, our respondents were more satisfied with the provided healthcare services (Table 3).

Male respondents considered a lack of financial resources and insufficient coordination as the biggest barrier in the implementation of the Health and Social Policy, while women considered the biggest barriers to be the indifference of society at large and insufficient political will. Our findings came as no surprise because the elderly are often perceived ${ }^{55}$ as a threat to the economy for being a burden on health care and welfare resources, while being perceived to currently make little contribution to the economy.

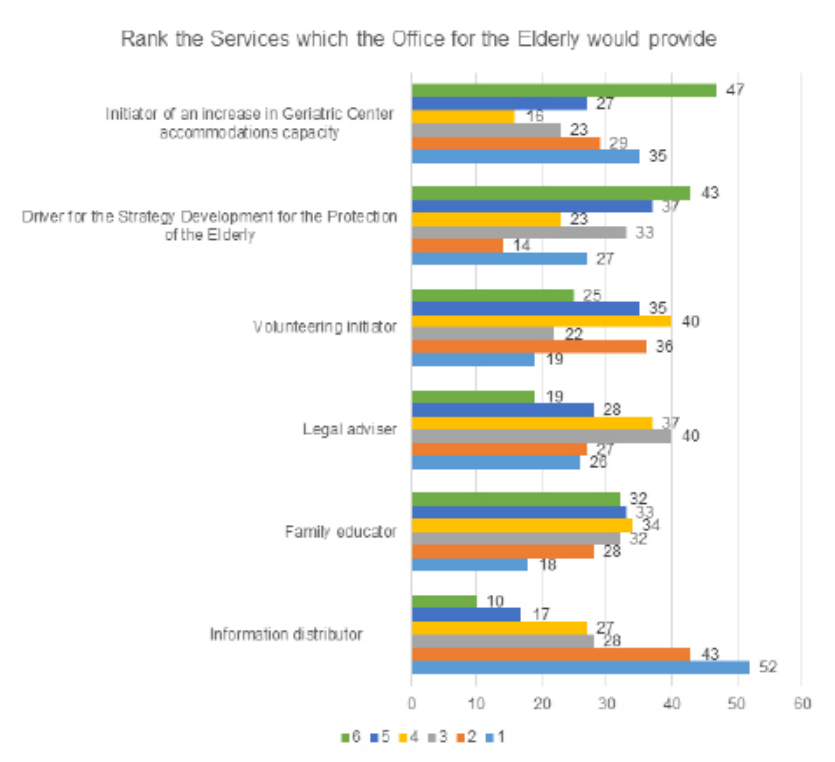

Figure 1: Comparison of the grading answers to question number 3. Respondents ranked the significance of the service that the Office for the Elderly would provide (indicating their first and most important answer with 1)
The analysis showed that there were statistically significant differences based on gender and education of respondents regarding the volunteering. Male respondents and respondents with Associate degrees and University degrees participated more frequently in volunteering activities than female respondents and respondents with high school educations. Similarly, there were statistically significant differences in gender and education regarding question 10. Namely, male respondents considered the institute for geriatrics and specialized counseling centers to be the institutions that would most significantly contribute to the improvement of the quality of healthcare for the elderly, while for the female respondents that would be the institute for geriatrics and the geriatric hospital. The most important institution for the university educated respondents was hospice, while for the other respondents, it was the institute of geriatrics. These answers show that various institutions focused on elderly are desired by our respondents. This is in line with the respondents answer to q2 (insufficient capacity of geriatric centers), bearing in mind that geriatric centers (homes) are the only institutional care centers for elderly in Serbia. ${ }^{9}$ Also, from the responses we can see that respondents chose few elderly focused institutions which, if implemented, could lead to the situation were elderly could stay longer in their own homes, due to the higher level of collaborative practice. $^{8}$ An average of $81 \%$ Europeans (for Serbia's bordering countries Croatia $71 \%$, Hungary $80 \%$, Romania $74 \%$ and Bulgaria $78 \%$ ) prefers to be cared for in their own homes either

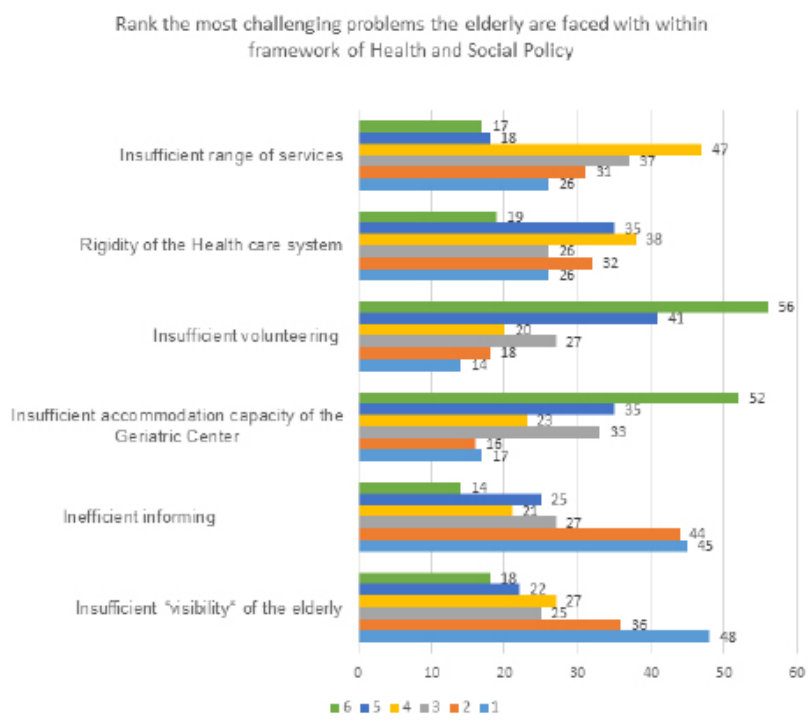

Figure 2: Comparison of the answers to question number 7 . Respondents ranked the significance of the problems the elderly are faced with, within the framework of Health and Social Policy (indicating their first and most important answer with 1) 
by relatives or professionals. ${ }^{7}$ On the other hand, in 2016, only 1\% of elderly in Serbia were covered by day care and home care services. ${ }^{9}$

Interesting insights in attitudes of the elderly towards $\mathrm{CPP}$ are found in section of the questionnaire describing the health workers teamwork in the context of improving the quality of life of the elderly. Of particular significance for our study were the results presented in Tables 2 and 3 , which are referred to respondents' answers about their attitudes and opinions regarding questions related to the conceptual model of collaborative pharmacy practice for the elderly. The results showed that the respondents believed that a pharmacist, as a member of the team of healthcare workers, who also offers counseling services on the rational and safe use of pharmacy products for the elderly, would contribute significantly to the improvement of health-related outcomes and the quality of life of the elderly. This view is justified and has foundation, since Spinewine A. et al. ${ }^{56}$ determined that the elderly patients who were involved in a collaborative pharmacy practice program were more likely to have increased both ACOVE (Assessing Care of the Elderly) and MAI (Medication Appropriateness Index), compared to a control group that was not included in the collaborative pharmacy practice program. The respondents of our study pointed out that they had rarely been in a situation where they were asked by a pharmacist to return to the doctor to have the therapy corrected. However, the respondents believed that the effectiveness of the health care system would have increased significantly if there had been even closer cooperation and coordination between doctors, pharmacists and other healthcare workers who provide care for the elderly. This view is confirmed by Nazir A. et al. ${ }^{57}$ where team coordination and communication were found as a key to successful collaborative practice with positive impact on patient outcomes. Also, Joint Commission on Accreditation of Healthcare Organizations, ${ }^{58}$ concluded that communication errors are the main cause of medical errors and delayed treatments, as well as the second most common cause of operative and post-operative incidents with fatal outcomes. Therefore, there is significant literature evidence that the view of our respondents is justified and healthcare system would benefit significantly if even closer cooperation and coordination between doctors, pharmacists and other healthcare workers who provide care for the elderly, could be achieved.

The traditional, culture term in Serbia corresponding to apothecary or druggist is "apotekar". The more contemporary term is pharmacist: "farmaceut". Therefore, it is worth noting that coordinators from the
Geriatric Centers had to clarify the word pharmacist, since the respondents were more familiar with the term corresponding to the word apothecary and as such they are perceived as located in a community pharmacy, or even merely as drug sales assistants. Consequently, based on the attitudes and responses of respondents, there was no collaborative pharmacy practice observed and pharmacists were not even perceived as healthcare workers. Therefore, the pharmacist together with the model of collaborative pharmacy practice represents an enormous unused asset in improving the health care for the elderly in a significant measure, which under the conditions of limited resources may require mainly organizational changes or corrections.

\section{Limitations and strengths}

An important limitation of study has to do with the fact that all of the respondents (population 65+) were patients of five publicly owned geriatric centers in one country and therefore, the study did not include senior responders living in their own homes, or responders from other countries. Another study limitation was the use of the term pharmacist in survey questionnaire instead of the term apothecary as more traditional term in Serbia. The strengths of the study include originality, rigor methodology, the amount of data tested and the fact that all the data used was primarily collected for the purpose of this study.

\section{Study implications}

The practical implication of the study can be found as a leverage for healthcare decision makers and a usable tool for other healthcare researchers. This study provides insights on what matters to the elderly regarding healthcare and social care system, which is the recommendation of $\mathrm{WHO}^{39}$ to optimize healthy ageing and the health care system as a whole. Keeping in mind that Serbia does not have a comprehensive long-term care policy that addresses the needs of the elderly population, ${ }^{9}$ our findings and prioritized needs by the elderly presented in our study, could be used by government and decision makers when creating that policy. Also, other researchers and decision makers could use our developed tool to research attitudes of the elderly towards ICP and CPP, so that they can better tailor their long-term care policy and collaborative practice for elderly, if necessary. Also, if used for that purpose, our research tool and study results could be used to check if changes in policies and CPP would make the changes in the attitudes of the elderly towards IPC and CPP in case that survey is repeated. This research is our contribution to provide more country data and help health systems 
to be more patient-centered and to improve universal health coverage and health equity for all population groups, especially to older adults as vulnerable group, which is all according to recommendations of WHO 's Thirteenth General Programme of Work 2019-2023. ${ }^{59}$

Further research may be deemed important to be conducted on the territory of the entire Republic of Serbia, as well as throughout Southeastern Europe, in order to gain an insight on the attitudes and beliefs of the wider population. Finally, our methods could be used to ascertain that users of healthcare services have positive attitudes towards CPP and IPC prior to any consideration of implementing CPP models by decision makers.

\section{CONCLUSION}

Our study shows that there are positive attitudes and beliefs of elderly population towards CPP and IPC. Gender and education as survey determinants are highly important when measuring elderly`s beliefs and attitudes. Bearing in mind that the respondents noted the insufficient visibility of the elderly and insufficient informing as the biggest problems faced by the elderly within the system of health-and social care, it is important to have better coordination of the aforementioned systems by having mediators or system navigators. The mediators would enable the elderly to become more familiar with options and services offered to them, which would increase the effectiveness of the health and social care systems.Lack of collaborative pharmacy practice represents a significant unused potential (asset) for improving health care for the elderly considerably, which under the conditions of limited resources, may stipulate organizational changes or corrections.

\section{ACKNOWLEDGEMENT}

Source of funding: Supported by Ministry of Education, Science and Technological Development Republic of Serbia: 451-03-68/2020-14/200161.

\section{CONFLICT OF INTEREST}

The authors declare no conflicts of interest.

\section{ABBREVIATIONS}

IPC: Interprofessional Cooperation; CPP: Collaborative Pharmacy Practices; GC: Geriatric Centre; OfE: Office for the Elderly; ACOVE: Assessing Care of the Elderly; MAI: Medication Appropriateness Index; ICC: Interclass Correlation Coefficient; EFA: Exploratory
Factor Analysis; LTCI: Long-Term Care Insurance; PACE: Program of All-Inclusive Care for the Elderly; IMPACT: Interprofessional Model of Practice for Aging and Complex Treatments; WHO: World Health Organization.

\section{REFERENCES}

1. United Nations. Department of Economic and Social Affairs, Population Division. World Population Ageing. New York: United Nation. 2015. [Cited 2018 July 27]. Available from: http://www.un.org/en/development/desa/ population/publications/pdf/ageing/WPA2015_Report.pdf.

2. Eurostat. Population structure and ageing. Luxembourg: Eurostat. 2017. [Cited 2018 October 10]. Available from: http://ec.europa.eu/eurostat/ statistics-explained/index.php/Population_structure_and_ageing.

3. United Nations Population Fund. Ageing in the Twenty-First Century: A Celebration and A Challenge. New York: United Nations Population Fund. 2012. [Cited 2018 July 27]. Available from: https://www.unfpa.org/sites/ default/files/pub-pdf/Ageing\%20report.pdf.

4. World Health Organization. Global Strategy and Action Plan on Ageing and Health (2016-2020): A Framework for Coordinated Global Action by the World Health Organization, Member States and Partners across the Sustainable Development Goals. Geneva: World Health Organization. 2016. [Cited 2018 November 29]. Available from: http://www.who.int/ageing/GSAP-SummaryEN.pdf?ua=1.

5. Ferrucci L, Giallauria F, Guralnik JM. Epidemiology of Aging. Radiol Clin North Am. 2008;46(4):643-52.

6. Cathcart G. Primary care in the driver's seat? Organizational reform in European primary care. Int J Dent Hyg. 2007;5(4):250-2.

7. Willemé P. The Long-Term Care System for the Elderly in Belgium. SSRN Electronic Journal. 2010.

8. Tsakitzidis G, Timmermans O, Callewaert N, Verhoeven V, Lopez-Hartmann $\mathrm{M}$, Truijen $\mathrm{S}$, et al. Outcome indicators on interprofessional collaboration interventions for elderly. Int J Integr Care. 2016;16(2).

9. Pejin SL, Bajec J. ESPN Thematic Report on Challenges in longterm care-Serbia. Brussels: European Commission. 2018. [cited 2020 May 2]. Available from: https://ec.europa.eu/social/main.jsp?pager. offset=20\&catld=792\&langld=en\&moreDocuments=yes.

10. Sauer M, Perišić N. Local Networks in the Provision of Long-term Care Services in Serbia - a View from the South-East of Europe. Sozialer Fortschritt. 2014;63(8):209-15.

11. Alberta Health Services. Collaborative Practice. Edmonton, Alta: Alberta Health Services. 2015. [cited 2020 May 2]. Available from: https://www. albertahealthservices.ca/assets/careers/ahs-careers-stu-supportinginterprofessional-placements.pdf.

12. Orchard C, Bainbridge L, Bassendowski S, Stevenson K, Wagner SJ, Weinberg $\mathrm{L}$, et al. A national interprofessional competency framework. Vancouver, BC: Canadian International Health Collaborative. 2010.

13. Ploeg J, Markle-Reid M, Fisher A, Morsy M, Dufour S, Reimer H, et al. Interprofessional education and interprofessional collaboration in home and community care of older adults and their families. Hamilton, Ont: Aging, Community and Health Research Unit. 2014.

14. D'amour D, Oandasan I. Interprofessionality as the field of interprofessional practice and interprofessional education: An emerging concept. J Interprof Care. 2005;19(sup1):8-20.

15. Boynton HM, Shute T, Rawlin D, Smith K, Willett T. Interprofessional education and care for seniors: An environmental scan. Ontario: SIM-one. 2013.

16. Zwarenstein M, Goldman J, Reeves S. Interprofessional collaboration: effects of practice-based interventions on professional practice and healthcare outcomes. Cochrane Database of Systematic Reviews: John Wiley and Sons, Ltd. 2009.

17. Trivedi D, Goodman C, Gage H, Baron N, Scheibl F, lliffe S, et al. The effectiveness of inter-professional working for older people living in the community: A systematic review. Health Soc Care Community. 2013;21(2):113-28. 
18. Tamiya N, Noguchi $\mathrm{H}$, Nishi A, Reich MR, Ikegami N, Hashimoto $\mathrm{H}$, et al. Population ageing and wellbeing: lessons from Japan's long-term care insurance policy. Lancet. 2011;378(9797):1183-92.

19. International Health Care System Profiles. The Danish Health Care System. Internet: The Commonwealth Fund. 2016. [cited 2020 May 3]. Available from: https://international.commonwealthfund.org/countries/denmark/.

20. The Ministry of Social Affairs and Integration. Social Policy in Denmark. Copenhagen: The Ministry of Social Affairs and Integration. 2011. [cited 2020 May 3]. Available from: http://www.oim.dk/media/14947/social-policyin-denmark.pdf.

21. Duner A. Care planning and decision-making in teams in Swedish elderly care: A study of interprofessional collaboration and professional boundaries. J Interprof Care. 2013;27(3):246-53.

22. Ling T, Brereton L, Conklin A, Newbould J, Roland M. Barriers and facilitators to integrating care: experiences from the English Integrated Care Pilots. Int $\mathrm{J}$ Integr Care. 2012;12(5).

23. Ministry of Health. Health of Older People Strategy: Health sector action to 2010 to support positive ageing. Wellington: Ministry of Health. 2001. [cited 2020 May 3]. Available from: https://www.health.govt.nz/system/files/ documents/publications/draftolderpeople.pdf.

24. National PACE Association. Understanding PACE. Alexandria, VA: National PACE Association. 2016. [cited 2020 May 3]. Available from: https://www. npaonline.org/sites/default/files/Profile\%20of\%20PACE_December\%20 2016.pdf.

25. Tracy CS, Bell SH, Nickell LA, Charles J, Upshur RE. The IMPACT clinic: Innovative model of interprofessional primary care for elderly patients with complex health care needs. Can Fam Physician. 2013;59(3):e148-55.

26. Bryant LJ, Coster G, Gamble GD, McCormick RN. The General PractitionerPharmacist Collaboration (GPPC) study: A randomised controlled trial of clinical medication reviews in community pharmacy. Int $\mathrm{J}$ Pharm Pract. 2011;19(2):94-105.

27. Denneboom W, Dautzenberg MG, Grol R, DeSmet PA. Treatment reviews of older people on polypharmacy in primary care: Cluster controlled trial comparing two approaches. Br J Gen Pract. 2007;57(542):723-31.

28. Barton A. Patient Safety and Quality: An Evidence-Based Handbook for Nurses. AORN J. 2009;90(4):601-2.

29. Donaldson MS, Corrigan JM, Kohn LT. To Err is Human: Building a Safer Health System. Washington, DC: National Academies Press. 2000.

30. Baker A. Book: Crossing the Quality Chasm: A New Health System for the 21st Century. BMJ. 2001;323(7322):1192.

31. Vass M, Avlund K, Hendriksen C, Philipson L, Riis P. Preventive home visits to older people in Denmark. Z Gerontol Geriatr. 2007;40(4):209-16.

32. Doucette WR, Nevins J, McDonough RP. Factors affecting collaborative care between pharmacists and physicians. Res Social Adm Pharm. 2005;1(4):56578.

33. Bradley F, Ashcroft DM, Noyce PR. Integration and differentiation: A conceptual model of general practitioner and community pharmacist collaboration. Res Social Adm Pharm. 2012;8(1):36-46.

34. Gallagher RM, Gallagher HC. Improving the working relationship between doctors and pharmacists: is inter-professional education the answer?. Advances in Health Sciences Education. 2010;17(2):247-57.

35. Risser DT, Rice MM, Salisbury ML, Simon R, Jay GD, Berns SD. The Potential for Improved Teamwork to Reduce Medical Errors in the Emergency Department. Ann Emerg Med. 1999;34(3):373-83.

36. Mickan S, Hoffman SJ, Nasmith L. Collaborative practice in a global health context: Common themes from developed and developing countries. J Interprof Care. 2010;24(5):492-502.

37. Petrovic M, Somers A, Onder G. Optimization of Geriatric Pharmacotherapy: Role of Multifaceted Cooperation in the Hospital Setting. Drugs Aging. 2016;33(3):179-88.

38. Ilic V, Marinkovic V, Tasic L. Conceptual model of collaborative pharmaceutical practice in healthcare and social care for the elderly. Vojnosanit Pregl. 2018;75(10):1020-9.

39. World Health Organization. World Report on Ageing and Health. Geneva: World Health Organization. 2015. [cited 2020 May 3]. Available from: https:// apps.who.int/iris/bitstream/handle/10665/186463/9789240694811_eng. pdf;jsessionid=0D03927D5205F091564D12A82D186F19? sequence=1.

40. Organisation mondiale de la santé. World Health organization, World Health Organization Staff. International classification of functioning, disability and health: ICF. World Health Organization. 2001.
41. Clarke P, Nieuwenhuijsen ER. Environments for healthy ageing: A critical review. Maturitas. 2009;64(1):14-9.

42. Institut za javno zdravlje Srbije "Dr Milan Jovanović-Batut". Izveštaj o unapređenju kvaliteta rada u zdravstvenim ustanovama Republike Srbije u 2013 godini, 2014. [Serbian Institute for Public Health“Dr Milan JovanovićBatut". Serbian Healthcare Institutions: Performance Improvement Report for 2013, 2014]. [cited 2018 August 8]. Available from: http://www.batut.org.rs/ download/izvestaji/2013_izvestaj_pokazatelji_kvaliteta.pdf.

43. Institut za javno zdravlje Srbije "Dr Milan Jovanović-Batut". Izveštaj o unapređenju kvaliteta rada u zdravstvenim ustanovama Republike Srbije u 2014 godini. 2015. [Serbian Institute for Public Health“Dr Milan JovanovićBatut". Serbian Healthcare Institutions: Performance Improvement Report for 2014, 2015]. [cited 2018 August 8]. Available from: http://www.batut.org.rs/ download/publikacije/lzvestaj\%20kvalitet\%202014.pdf.

44. Milutinović D, Lovrić R, Simin D. Interprofessional education and collaborative practice: Psychometric analysis of the Readiness for Interprofessional Learning Scale in undergraduate Serbian healthcare student context. Nurse Educ Today. 2018;65:74-80.

45. Simin D, Novakovic B, Brestovacki-Svitlica B, Vujkov S, Milutinovic D. New strategy in education of health professionals in Serbia: Analysis of students' readiness for inter-professional education. Med Pregl. 2018;71(suppl 1):9-16.

46. Odalović M, Parojčić J, Vasiljević D, Đukić ĆD, Tasić L. Reinforcement of the Framework for Experiential Education in Healthcare in Serbia: PostImplementation Project Review within Pharmacy Education. Pharmacy. 2019;7(3):92.

47. Institut za javno zdravlje Srbije "Dr Milan Jovanović-Batut". Analiza zadovoljstva krisnika zdravstvenom zaštitom u državnim zdravstvenim ustanovama Republike Srbije 2018. godine. [Serbian Institute for Public Health“Dr Milan Jovanović-Batut”. Serbian Publicly Owned Healthcare Institutions: Analysis of users' satisfaction in 2018.]. [cited 2020 May 5]. Available from: http://www.batut.org.rs/download/izvestaji/Analiza\%20 zadovoljstva\%20korisnika\%202018.pdf

48. Thannhauser J, Russell-Mayhew S, Scott C. Measures of interprofessional education and collaboration. J Interprof Care. 2010;24(4):336-49.

49. Lindqvist S, Duncan A, Shepstone L, Watts F, Pearce S. Development of the "Attitudes to Health Professionals Questionnaire" (AHPQ): A measure to assess interprofessional attitudes. J Interprof Care. 2005;19(3):269-79.

50. Körner M. Interprofessional teamwork in medical rehabilitation: A comparison of multidisciplinary and interdisciplinary team approach. Clin Rehabil. 2010;24(8):745-55.

51. Parsell G, Bligh J. The development of a questionnaire to assess the readiness of health care students for interprofessional learning (RIPLS). Med Educ. 1999;33(2):95-100.

52. World Health Organization. Global Strategy and Action Plan on Ageing and Health. Geneva: World Health Organization. 2015. [cited 2020 May 5]. Available from: https://www.who.int/ageing/WHO-GSAP-2017.pdf?ua=1.

53. Cutler D, Lleras-Muney A. Education and Health: Evaluating Theories and Evidence. NBER Work Pap Ser. 2006.

54. Buttigieg SC, llinca S, DeSao JJMS, Larsson AT. Researching Ageism in Health-Care and Long Term Care. Contemporary Perspectives on Ageism. 2018;493-515.

55. Swift HJ, Abrams D, Marques S, Vauclair CM, Bratt C, Lima ML. Ageism in the European Region: Finding from the European Social Survey. Contemporary Perspectives on Ageism. 2018;441-59.

56. Spinewine A, Swine C, Dhillon S, Lambert P, Nachega JB, Wilmotte L, et al. Effect of a Collaborative Approach on the Quality of Prescribing for Geriatric Inpatients: A Randomized, Controlled Trial. Geriatrics. 2007;55(5):658-65.

57. Nazir A, Unroe K, Tegeler M, Khan B, Azar J, Boustani M. Systematic Review of Interdisciplinary Interventions in Nursing Homes. J Am Med Dir Assoc. 2013;14(7):471-8.

58. Joint Commission on Accreditation of Healthcare Organizations. The Joint Commission guide to improving staff communication. Oakbrook Terrace, IL: Joint Commission Resources. 2005.

59. World Health Organization. The Thirteenth General Programme of Work, 2019-2023. Geneva: World Health Organization. 2019. [cited 2020 May 5]. Available from: https://apps.who.int/iris/bitstream/handle/10665/324775/ WHO-PRP-18.1-eng.pdf. 


\section{PICTORIAL ABSTRACT}

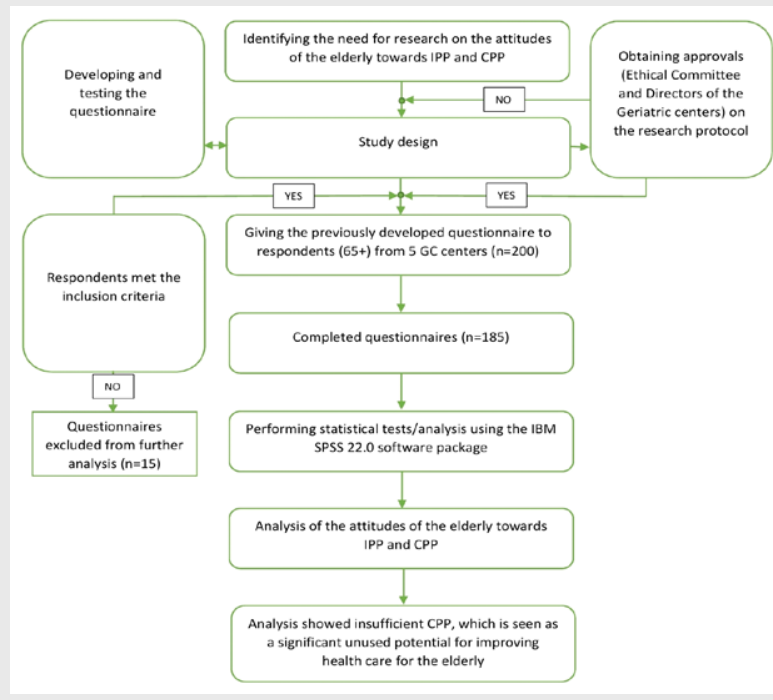

\section{SUMMARY}

A previously developed structured questionnaire was used as an instrument in a cross-sectional study in Serbia in order to research the attitudes of the elderly people $(65+)$ towards IPC and CPP. The analysis showed that the sample size was adequate and that previously developed questionnaire provided interesting results from various statistical tests. Respondents of both genders believed that the efficiency of the healthcare system would increase significantly if there were closer cooperation and coordination between doctors and pharmacist and other healthcare workers. Therefore, the lack of collaborative pharmacy practice represents a significant unused potential (asset) for improving health care for the elderly considerably. Even in developing countries, under the conditions of limited resources, reform of the healthcare system towards improving its performance may stipulate just organizational changes or corrections.

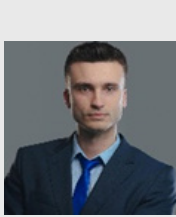

\section{About Authors}

Velibor O llic, is a Ph.D candidate at the Faculty of Pharmacy, University of Belgrade, Department of Social Pharmacy and Pharmaceutical Legislation. At the same University he completed postgraduate program of specialist academic studies in Pharmaceutical management and marketing. He was born in Novi Sad, where he obtained B.Sc and M.Sc degree at Faculty of Economics Subotica, University of Novi Sad. From 2014 until 2018, he was a member of Serbian team for healthcare research in COST action (IS 1402). His research interest are: healthcare collaboration, health policy and ageism.

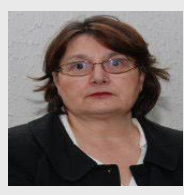

Ljiljana Tasic, is a full Professor and founder in the Department of Social Pharmacy and Pharmaceutical Legislation, Faculty of Pharmacy in Belgrade University; teaching students in the field of Pharmacy Practice, health management, medicines policy, pharmacoepidemiology and quality in the health care. From 2012 she is Director of Center for development of Pharmacy Practice. During 2014 she has position of Visiting Professor at University of Queensland (AU) She has also published about 170 publication, 13 chapter in monographs and books, 4 books. Her research interest are: pharmacists' education, public health, quality in medicines use (in elderly, in pregnancy).

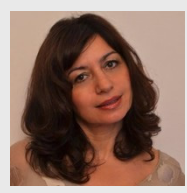

Valentina D. Marinkovic is a full Professor and Head of the Department for Social Pharmacy and Pharmacy Legislation at the Faculty of Pharmacy, University of Belgrade. She obtained BSc, MSc, $\mathrm{PhD}$ at the Faculty of Pharmacy, University of Belgrade, in the field of pharmaceutical chemistry. Valentina Marinkovic's professional career built in two directions - academic and work in practice. She established practical experience in the pharmaceutical and chemical industry at the position of Quality director in multinational companies. Recently, she was visiting researcher at RWTH University of Aachen, Germany.

Cite this article: llić VO, Tasić L, Marinković V. Research on the Attitudes of the Elderly towards Interprofessional Cooperation and Collaborative Pharmacy Practices: Cross-sectional Study in Serbia. Indian J of Pharmaceutical Education and Research. 2021;55(1):276-87. 